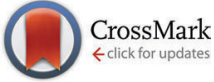

Cite this: Chem. Commun., 2015, 51, 17285

Received 26th July 2015, Accepted 5th October 2015

DOI: $10.1039 / c 5 c c 06256 j$

www.rsc.org/chemcomm

\section{Hydrophilic non-precious metal nitrogen-doped carbon electrocatalysts for enhanced efficiency in oxygen reduction reaction $\dagger$}

\author{
Guang-Ping Hao, ${ }^{a}$ Nastaran Ranjbar Sahraie, ${ }^{b}$ Qiang Zhang, ${ }^{c}$ Simon Krause, ${ }^{a}$ \\ Martin Oschatz, ${ }^{a}$ Alicja Bachmatiuk, ${ }^{\text {de }}$ Peter Strasser ${ }^{\star b}$ and Stefan Kaskel*af
}

\begin{abstract}
Exploring the role of surface hydrophilicity of non-precious metal $\mathrm{N}$-doped carbon electrocatalysts in electrocatalysis is challenging. Herein we discover an ultra-hydrophilic non-precious carbon electrocatalyst, showing enhanced catalysis efficiency on both gravimetric and areal basis for oxygen reduction reaction due to a high dispersion of active centres.
\end{abstract}

The oxygen reduction reaction (ORR) is a fundamental electrochemical reaction for fuel cells and metal-air batteries. ORR research has long been focused on the development and understanding of new non-precious nitrogen-doped carbon catalysts that result in significant cost reduction by platinum metal substitution. To catalyze broader commercialization of such devices and technologies, efficient and affordable non-precious electrocatalysts will ultimately be required. One of the most prominent examples is pyrolyzed solid materials consisting of non-precious metal/nitrogen/carbon (M/N/C-) composites, ${ }^{1}$ or metal-free, heteroatom-doped nanocarbons. ${ }^{2}$ The nature of the active sites in terms of the modulation of electron donating/ withdrawing capability of the carbon basal plane by incorporated heteroatoms of the $\mathrm{M} / \mathrm{N} / \mathrm{C}$ electrocatalysts has been under intensive investigation and has become more and more clear. ${ }^{3}$ However, a detailed understanding of the effect of surface

\footnotetext{
${ }^{a}$ Department of Inorganic Chemistry, Technische Universität Dresden, Bergstraße 66, 01069 Dresden, Germany. E-mail: Stefan.Kaskel@chemie.tu-dresden.de

${ }^{b}$ The Electrochemical Energy, Catalysis, and Materials Science Laboratory, Department of Chemistry, Chemical Engineering Division,

Technical University Berlin, Straße des 17. Juni 124, 10623 Berlin, Germany. E-mail: pstrasser@tu-berlin.de

${ }^{c}$ Beijing Key Laboratory of Green Chemical Reaction Engineering and Technology, Department of Chemical Engineering, Tsinghua University, Beijing 100084,

P. R. China

${ }^{d}$ IFW Dresden, Institute of Complex Materials, P. O. Box 270116, D-01171, Dresden, Germany

${ }^{e}$ Center of Polymer and Carbon Materials, Polish Academy of Sciences, M. Curie-Sklodowskiej 34, Zabrze 41-819, Poland

${ }^{f}$ Fraunhofer Institute for Material and Beam Technology, Winterbergstraße 28, 01277, Dresden, Germany

$\dagger$ Electronic supplementary information (ESI) available. See DOI: 10.1039/c5cc06256j
}

hydrophilicity and wettability on the dispersion of metal-related active sites as well as their effects on the catalysis efficiency of the $\mathrm{M} / \mathrm{N} / \mathrm{C}$ materials has remained elusive.

On the one hand, a hydrophilic pore surface benefits a facile loading and a high dispersion of active metal-related species, because hydrophilic affinity can be created between hydrophilic pore walls and precursors, and further inhibits precursor random migration and agglomeration. ${ }^{4}$ On the other hand, a hydrophilic pore surface may also influence the transport of hydrated $\mathrm{O}_{2}$ to the electrochemically active centres under hydrated conditions, finally affecting the activity. ${ }^{5}$ To our knowledge, such effects stemming from surface hydrophilicity have been rarely investigated to date.

Taking these into consideration, in this contribution, we surface engineered a number of different carbon-based materials with surface characteristics ranging from an ultra-hydrophilic carbon network to an ultra-hydrophobic carbon black. We observe that hydrophilicity, quantified by water adsorption isotherms at $298 \mathrm{~K}$, is correlated with much enhanced ORR catalysis efficiency.

Firstly, a group of ultra-hydrophilic electrocatalysts (Fe/N_1/3.2, $\mathrm{Fe} / \mathrm{Cu} / \mathrm{N} \_1.3 / 1 / 8$, and $\mathrm{Cu} / \mathrm{N} \_1 / 4$, according to the nominal atomic ratio of $\mathrm{Fe} / \mathrm{N}, \mathrm{Fe} / \mathrm{Cu} / \mathrm{N}$ and $\mathrm{Cu} / \mathrm{N}$ in the synthesis, Fig. 1a-c) were fabricated by a facile and scalable impregnation and subsequent pyrolysis and leaching method (Experimental section, ESI $\dagger$ ) based on an unprecedentedly hydrophilic carbon network (DUT-110, DUT $=$ Dresden University of Technology, derived from a functional complex $\left.{ }^{6}\right)$. The highly hydrophilic surface property of DUT-110 was confirmed by the sharp uptake in the water vapor adsorption isotherm from the very beginning, showing a record value until $P / P_{0}<0.3$ (Fig. S1a, ESI $\dagger$ ). ${ }^{7}$ The narrow and rich micropores were proven by the type I isotherm and pore size distribution based on $\mathrm{N}_{2}$ physisorption data (Fig. S1b, ESI $\dagger$ ) as well as high resolution TEM images (Fig. S1c, ESI $\dagger$ ); while the STEM mapping and XPS spectrum revealed the highly heteroatomdoped feature, with a surface composition of $\mathrm{C}, \mathrm{N}$, and $\mathrm{O}$ with the atomic content of $74.7,14.3$, and $10.33 \%$, respectively (Fig. S1d and e, ESI $\dagger$ ). In parallel, hydrophobic non-precious electrocatalysts 

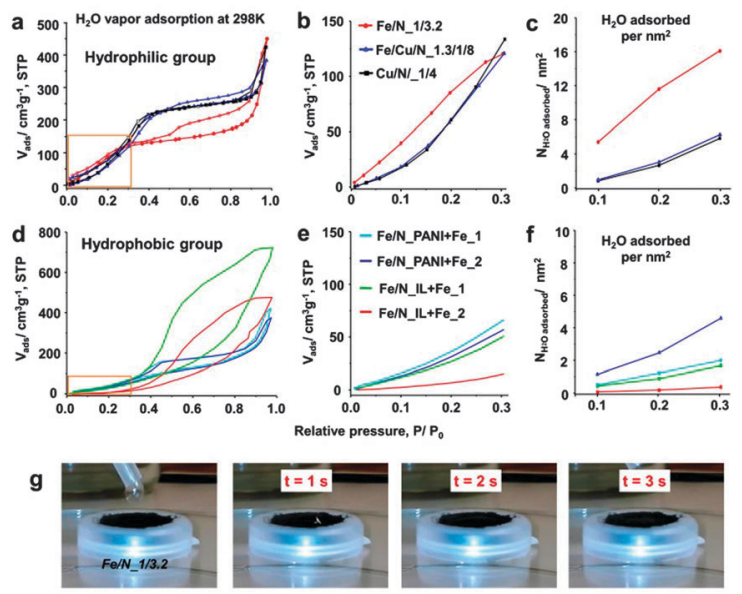

h
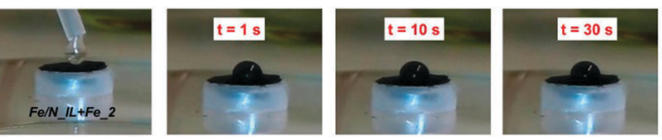

Fig. $1 \mathrm{H}_{2} \mathrm{O}$ vapor adsorption isotherm at different relative pressure range at $298 \mathrm{~K}$ of hydrophilic groups $(\mathrm{a}-\mathrm{c})$ and hydrophobic groups $(\mathrm{d}-\mathrm{f})$. ( $\mathrm{g}$ and $\mathrm{h}$ ) Comparison of dynamic water contact angle changes of typical samples of the two groups.

were prepared under the same principle through the modification of N-containing polymers (polyaniline, PANI or N-containing ionic liquid, $N, N$-ethyl-methyl-imidazolium-dicyanamide) and $\mathrm{FeCl}_{3}$, but based on highly hydrophobic carbon black (Ketjen EC 600J). Note that the pyrolysis and leaching treatment as well as the following performance evaluation were kept identical with those of the hydrophilic groups.

Surprisingly, the final hydrophilic electrocatalysts, Fe/N_1/3.2, $\mathrm{Fe} / \mathrm{Cu} / \mathrm{N} \_1.3 / 1 / 8$, and $\mathrm{Cu} / \mathrm{N} \_1 / 4$, maintained largely the high surface hydrophilicity. They all exhibit relatively good hydrophilic properties, with the water uptake of $120.4,120.5$, and $133.6 \mathrm{~cm}^{3} \mathrm{~g}^{-1}$ (equivalent to $5.37,5.38$, and $5.96 \mathrm{mmol} \mathrm{g}^{-1}$ ) at $P / P_{0}=0.3$ for $\mathrm{Fe} / \mathrm{N} \_1 / 3.2, \mathrm{Fe} / \mathrm{Cu} / \mathrm{N} \_1.3 / 1 / 8$, and $\mathrm{Cu} / \mathrm{N} \_1 / 4$, respectively (Fig. 1a). The water adsorption behavior in the range of $0<P / P_{0}<0.3$ is mainly determined by the surface hydrophilicity; ${ }^{7}$ thus, we further compared the water sorption uptake in this pressure range (Fig. 1b). All the hydrophilic samples, i.e., $\mathrm{Fe} / \mathrm{N} \_1 / 3.2, \mathrm{Fe} / \mathrm{Cu} / \mathrm{N} \_1.3 / 1 / 8$, and $\mathrm{Cu} / \mathrm{N} \_1 / 4$, exhibit a higher water adsorption uptake, even though their less developed porosity and low surface area $\left(200-574 \mathrm{~m}^{2} \mathrm{~g}^{-1}\right.$, Fig. S2, ESI $\left.\dagger\right)$ were comparable to hydrophobic materials $\left(340-1079 \mathrm{~m}^{2} \mathrm{~g}^{-1}\right.$, Table S1, ESI $\dagger$ ). After normalization to specific surface area (Fig. 1c), the hydrophilicity order is Fe/N_1/3.2 > Fe/Cu/N_1.3/1/8 > Cu/N_1/4. For instance, the water adsorption uptake is calculated to be 16.2 $\mathrm{H}_{2} \mathrm{O}$ molecules per $\mathrm{nm}^{2}$, $6.7 \mathrm{H}_{2} \mathrm{O}$ molecules per $\mathrm{nm}^{2}$ and $6.2 \mathrm{H}_{2} \mathrm{O}$ molecules per $\mathrm{nm}^{2}$ at $P / P_{0}=0.3$ for Fe/N_1/3.2, Fe/Cu/N_1.3/1/8, and $\mathrm{Cu} / \mathrm{N} \_1 / 4$, respectively. However, the water adsorption isotherm of the hydrophobic electrocatalysts displays much lower water adsorption uptakes, indicating a much lower surface hydrophilicity (Fig. 1d-f). To illustrate the difference in hydrophilicity vividly, the water contact angles were recorded dynamically after water droplets contacted the carbon pellet and were compared (herein we show the samples of Fe/N_1/3.2 and Fe/N_IL + Fe_2 in Fig. $1 \mathrm{~g}$ and $\mathrm{h}$ ). For hydrophilic Fe/N_1/3.2, the water droplet can be adsorbed in $3 \mathrm{~s}$ with a final contact angle of $c a$. 0 , while the sample of Fe/N_IL $+\mathrm{Fe} \_2$ was not wetted until $30 \mathrm{~s}$, again confirming the distinct surface hydrophilicity. Morphologically, all the hydrophilic electrocatalysts exhibit a highly interconnected network structure (Fig. S3, ESI $\dagger$ ), but a much denser structure compared with their host carbon networks DUT-110 (Fig. S1d, $\mathrm{ESI} \dagger$ ). This is due to the shrinkage of the carbon skeletons during high temperature pyrolysis.

Based on the unique hydrophilicity and narrow micropores, a high dispersion of metal-related nanoparticles was expected for hydrophilic electrocatalysts. Thus, the elemental distribution was analysed by STEM images and elemental maps as well as dark-field TEM images (Fig. 2). For Fe/N_1/3.2 (Fig. 2a), large and bright particles can be observed, while for $\mathrm{Fe} / \mathrm{Cu} / \mathrm{N} \_1.3 / 1 / 8$, only very few isolated particles can be detected (Fig. 2b). This observation is consistent with the TEM images (Fig. S4, ESI $\dagger$ ). Importantly, except some large particles, the distribution of small metal species is very homogeneous, indicating highly dispersed nanoclusters or even mononuclear metal species embedded in the carbon matrix. The dark-field TEM images (Fig. 2e and f), corresponding to their relevant TEM images (Fig. 2c and d), again confirmed a high and uniform distribution of metal-related nanoclusters over the whole framework. The metal content determined by the ICP technique is $3.8 \mathrm{wt} \% \mathrm{Fe}$ for $\mathrm{Fe} / \mathrm{N} \_1 / 3.2$ and $1.22 \mathrm{wt} \% \mathrm{Fe}$ for $\mathrm{Fe} / \mathrm{N} \_1 / 3.2$. Note that these metal nanoclusters should be tightly embedded in the carbon matrix, since all these electrocatalysts have been extensively leached in $2.0 \mathrm{M}$ $\mathrm{H}_{2} \mathrm{SO}_{4}$ at $110{ }^{\circ} \mathrm{C}$ for $24 \mathrm{~h}$ before harvesting for characterisation and application. Furthermore, the hybrid structure composed of graphitic domains and amorphous carbons was revealed by Raman spectra (Fig. S5, fitting details in Table S2, ESI $\dagger$ ) with the $I_{\mathrm{D}} / I_{\mathrm{G}}$ ratio of $1.55,1.82$ and 2.11 for $\mathrm{Fe} / \mathrm{N} \_1 / 3.2, \mathrm{Fe} / \mathrm{Cu} / \mathrm{N} \_1.3 / 1 / 8$ and $\mathrm{Cu} / \mathrm{N} \_1 / 4$, respectively, confirming the observation by TEM images (Fig. S4, ESI $\dagger$ ).

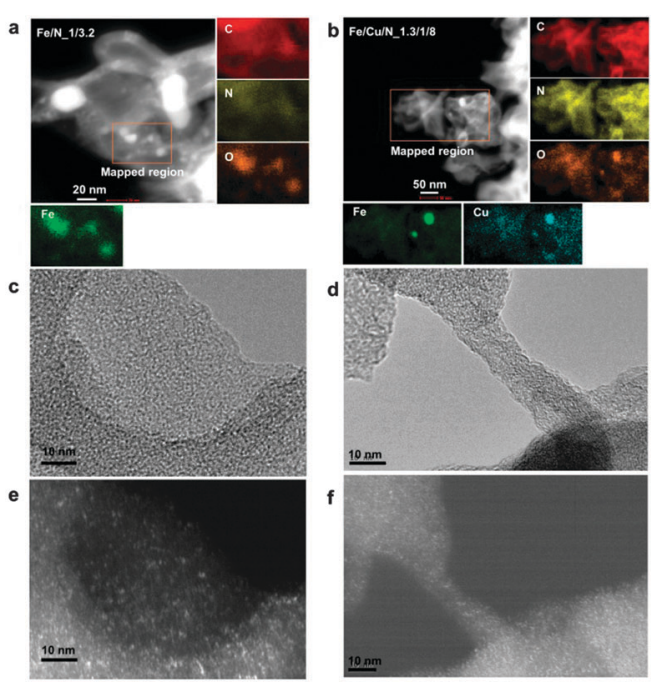

Fig. 2 STEM maps of Fe/N_1/3.2 (a) and Fe/Cu/N_1.3/1/8 (b), TEM image and the corresponding dark-field TEM images of Fe/N_1/3.2 (c and e) and $\mathrm{Fe} / \mathrm{Cu} / \mathrm{N} \_1.3 / 1 / 8$ (d and f). 
For non-metal elements such as $\mathrm{C}, \mathrm{O}$, and $\mathrm{N}$, a homogeneous dispersion was also observed by elemental maps (Fig. 2a and b), indicating a uniform doped structure. Interestingly, comparing the $\mathrm{Fe}$ or $\mathrm{Cu}$ maps with $\mathrm{O}$ maps, a strong correlation is found between the metal and $\mathrm{O}$, particularly for large particles, indicating their oxide phase in nature. This observation is further confirmed by their XPS analysis (Fig. S6, ESI $\dagger$ ). Furthermore, Table S1 (ESI $\dagger$ ) also lists other structural parameters such as the specific surface area analyzed by $\mathrm{N}_{2}$ adsorption, the surface non-metal compositions determined by XPS and the metal species detected by ICP for all the hydrophilic and hydrophobic catalyst groups in order to obtain a reliable correlation between the structural parameters and the subsequent catalysis performance.

We first evaluated the ORR activity of the hydrophilic group, i.e., $\mathrm{Fe} / \mathrm{N} \_1 / 3.2, \mathrm{Fe} / \mathrm{Cu} / \mathrm{N} \_1.3 / 1 / 8$, and $\mathrm{Cu} / \mathrm{N} \_1 / 4$. Linear sweep voltammetry (LSV, Fig. 3a) in $0.10 \mathrm{M} \mathrm{KOH}$ was employed to investigate the catalytic activity of the catalysts compared to $\mathrm{Pt} / \mathrm{C}$ benchmark catalysts. The onset potentials $\left(E_{\text {onset }}\right.$, a noteworthy onset potential is defined as the potential at which the current density reaches $1.0 \mathrm{~mA} \mathrm{~cm}^{-2}$ ) are $0.90,0.92$, and $0.89 \mathrm{~V}$ for $\mathrm{Fe} / \mathrm{N} \_1 / 3.2, \mathrm{Fe} / \mathrm{Cu} / \mathrm{N} \_1.3 / 1 / 8$, and $\mathrm{Cu} / \mathrm{N} \_1 / 4$, respectively (Fig. 3a, Table S1, ESI $\dagger$ ). The $E_{\text {onset }}$ of $\mathrm{Fe} / \mathrm{Cu} / \mathrm{N} \_1.3 / 1 / 8$ is positive and comparable with those of the reported state-of-the-art nonprecious catalysts such as Fe/N-doped nanocarbons (e.g. N-CNT/ $\mathrm{Fe}_{3} \mathrm{C}$, N-doped carbon nanoplate $/ \mathrm{Fe}_{3} \mathrm{C}$, Fe@Fe $\mathrm{F}_{3} \mathrm{C} / \mathrm{N}$-doped carbon), ${ }^{8} \mathrm{Fe}$ and/or N-doped porous carbons with higher surface area or larger pores such as mesopores ${ }^{9}$ or hierarchical pores, ${ }^{10}$ and the hybrid N-Fe-CNT/carbon nanoparticle with higher Fe content. ${ }^{11}$ The half-wave potential $\left(E_{1 / 2}\right)$ shows a similar trend that is also comparable with that of the state-of-the-art non-precious
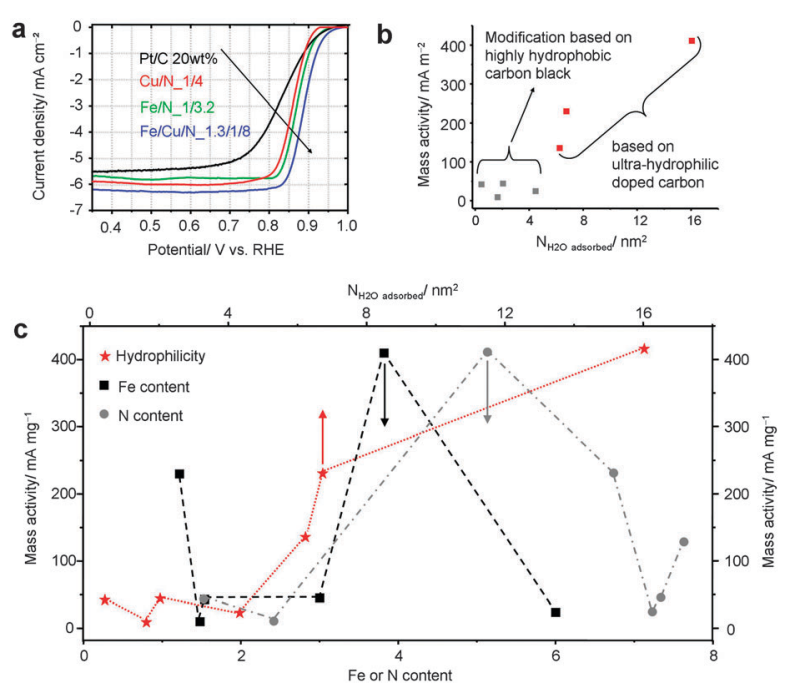

Fig. 3 ORR catalysis evaluation in $\mathrm{O}_{2}$-saturated $0.10 \mathrm{M} \mathrm{KOH}$. (a) Linear sweep voltammetry (LSV) ORR plots under conditions of room temperature, at a rotation speed of $1500 \mathrm{rpm}$, scan rate of $10 \mathrm{mV} \mathrm{s}^{-1}$, the nonprecious catalysts loading of $0.80 \mathrm{mg} \mathrm{cm}^{-2}$, and the benchmark Pt loading of $10 \mu \mathrm{g} \mathrm{cm}^{-2}$. (b) The relationship between hydrophilicity in terms of water molecules adsorbed per $\mathrm{nm}^{2}$ based on water adsorption data at $P / P_{0}=0.3$ and mass activity. (c) Structure-performance comparison including surface hydrophilicity, nitrogen content (atomic\%, by XPS) and Fe content (wt\%, by ICP) with mass activity in ORR electrocatalysis under identical conditions. electrocatalysts (Table S3, ESI $\dagger$ ). ${ }^{9-12}$ Particularly, the high activity reflected by the positive $E_{\text {onset }}$ and $E_{1 / 2}$ of $\mathrm{Fe} / \mathrm{Cu} / \mathrm{N}_{-} 1.3 / 1 / 8$ originates from the highly dispersed active sites and highly accessible porosity.

The mass activity indicates the utilization efficiency of catalysts on a gravimetric basis. For the hydrophilic series, relatively higher mass activities up to 413.3, 232.5, and $137.7 \mathrm{mAmg}^{-1}$ were calculated for $\mathrm{Fe} / \mathrm{N} \_1 / 3.2, \mathrm{Fe} / \mathrm{Cu} / \mathrm{N} \_1.3 / 1 / 8$, and $\mathrm{Cu} / \mathrm{N} \_1 / 4$, respectively (Fig. 3b). For the hydrophobic samples, the mass activity is one order of magnitude lower (Fig. 3b). The much higher mass activity of the hydrophilic samples originated from the positively shifted onset and half-wave potentials, indicating the large density of accessible active sites due to the high dispersion of electrochemically active sites benefiting from the highly hydrophilic carbon surface. In order to understand quantitatively, we further normalized the mass activity by the surface area. The obtained specific activities are 2067, 482.4, and $239.9 \mathrm{~mA} \mathrm{~m}^{-2}$ for $\mathrm{Fe} / \mathrm{N} \_1 / 3.2, \mathrm{Fe} / \mathrm{Cu} / \mathrm{N} \_1.3 / 1 / 8$, and $\mathrm{Cu} / \mathrm{N} \_1 / 4$, respectively. This trend is also consistent with that of mass activity, reflecting the remarkably high surface efficiency (Fig. S7 and Table S1, ESI $\dagger$ ).

Moreover, we correlated the $\mathrm{Fe}$ and $\mathrm{N}$ content, and the surface area as well as surface hydrophilicity with mass activity. However, it is difficult to find a clear trend between either mass or specific activity and doping properties (Fig. 3c, black and grey lines, Fig. S8, ESI $\dagger$ ) or specific surface area (Table S1 and Fig. S9, ESI $\dagger$ ). In contrast, a clear correlation between mass activity and surface hydrophilicity was observed. This is probably because (1) the higher surface hydrophilicity induces a higher dispersion of active sites, and (2) hydrophilic pores benefit an easy accessibility to the active sites of reactants (such as hydrated $\mathrm{O}_{2}$ as ORR proceeds). Besides the comparison between specific samples, a comparison between the hydrophobic group and the ultra-hydrophilic group confirmed the same rule (Fig. 3c, red trend line).

The high dispersion of active sites benefiting from surface hydrophilicity has been proven above by STEM mapping and dark field TEM images. However, to observe the effect of hydrophilicity on the diffusion of hydrated $\mathrm{O}_{2}$ and resultant $\mathrm{H}_{2} \mathrm{O}$ is challenging. For the diffusion of hydrated $\mathrm{O}_{2}$ near reaction interfaces, high surface hydrophilicity may be beneficial. ${ }^{5 b-d}$ In order to explain this point, we hypothesized a "physical structure" (Fig. S10, ESI $\dagger$ ), where water molecules around hydrated $\mathrm{O}_{2}$ molecules can be readily stripped by the hydrophilic micropore walls when approaching the carbon slit pores, then the liberated $\mathrm{O}_{2}$ molecules can freely diffuse to the active sites and thus can accelerate the reaction. The $\mathrm{O}_{2}$ adsorption was investigated for the active hydrophilic group, which can give the first clue that high surface hydrophilicity enhanced the $\mathrm{O}_{2}$ adsorption (Fig. S11, ESI $\dagger$ ). All hydrophilic samples exhibit a combined type I isotherm (Fig. S9a and b ESI $\dagger$ ), indicating a strong interaction between $\mathrm{O}_{2}$ molecules and doped carbon pore walls. After normalization by the specific surface area, the samples showed a higher areal uptake, indicating the preferential $\mathrm{O}_{2}$ adsorption and high surface utilization efficiency for trapping $\mathrm{O}_{2}$ molecules (Fig. S11c, ESI $\dagger$ ). Interestingly, the $\mathrm{O}_{2}$ capture behaviour is consistent with that of water sorption in the same pressure range. 
In addition, one would realize that the high surface hydrophilicity of the catalysts may also cause a delay of water desorption when used in applications that generate water such as alkaline fuel cells (AFCs). In this case, further $\mathrm{H}_{2}$ reduction can be applied to effectively reduce the surface hydrophilicity (Fig. S12, ESI $\dagger$ ). Through this way, the possible flooding issues can be avoided in potential applications such as AFCs.

In summary, exemplified using the non-precious carbon based ORR electrocatalyst concept, we surface engineered a number of different carbon based materials with surface characteristics ranging from an ultra-hydrophilic carbon network to ultra-hydrophobic carbon black. A high surface hydrophilicity has been found to give an easily wetted surface which first ensures a high dispersion of metal-related active sites and may also increase the accessibility of reactants to active centres, and thus may increase the surface and mass utilization efficiency of catalysts. This work provides fresh insight into the controlling material parameters of non-precious ORR catalysts, and as such offers new clues and strategies on how to increase the ORR catalysis efficiency by tuning the surface chemistry of nonprecious electrocatalysts. The insight into hydrophilicity may also be important to other heterogeneous catalytic reactions such as $\mathrm{CO}_{2}$ electro-reduction, glucose oxidation, and metal-air batteries, catalyzed on hydrated carbon surfaces.

We thank Prof A. Eychmüller and S. Klosz for Raman spectra measurement, Dr I. Senkovska for help in the $\mathrm{O}_{2}$ adsorption measurement. G.-P. H. acknowledges the financial support from the Alexander von Humboldt Foundation.

\section{Notes and references}

1 (a) M. Lefèvre, E. Proietti, F. Jaouen and J.-P. Dodelet, Science, 2009, 324, 71; (b) F. Jaouen, E. Proietti, M. Lefèvre, R. Chenitz, J.-P. Dodelet, G. Wu, H. T. Chung, C. M. Johnston and P. Zelenay, Energy Environ. Sci., 2011, 4, 114; (c) G. Wu, K. L. More, C. M. Johnston and P. Zelenay, Science, 2011, 332, 443; (d) M. K. Debe, Nature, 2012, 486, 43; (e) K. Wood, R. O'Hayre and S. Pylypenko, Energy Environ. Sci., 2014, 7, 1212; $(f)$ D.-W. Wang and D. Su, Energy Environ. Sci., 2014, 7, 576; ( $g$ ) G. Wu and P. Zelenay, Acc. Chem. Res., 2013, 46, 1878.

2 (a) K. Gong, F. Du, Z. Xia, M. Durstock and L. Dai, Science, 2009, 323, 760; (b) L. Qu, Y. Liu, J.-B. Baek and L. Dai, ACS Nano, 2010,
4, 1321; (c) W. Wei, H. Liang, K. Parvez, X. Zhuang, X. Feng and K. Müllen, Angew. Chem., Int. Ed., 2014, 53, 1570; (d) Y. Jiao, Y. Zheng, M. Jaroniec and S. Z. Qiao, J. Am. Chem. Soc., 2014, 136, 4394; (e) J. Liang, Y. Jiao, M. Jaroniec and S. Z. Qiao, Angew. Chem., Int. Ed., 2012, 51, 11496; $(f)$ D. Yu, Q. Zhang and L. Dai, J. Am. Chem. Soc., 2010, 132, 15127.

3 (a) J.-L. Shui, N. K. Karan, M. Balasubramanian, S.-Y. Li and D.-J. Liu, J. Am. Chem. Soc., 2012, 134, 16654; (b) N. Ramaswamy, U. Tylus, Q. Jia and S. Mukerjee, J. Am. Chem. Soc., 2013, 135, 15443; (c) Y. Zhu, B. Zhang, X. Liu, D.-W. Wang and D. Su, Angew. Chem., Int. Ed., 2014, 53, 10673; (d) U. I. Kramm, M. Lefèvre, N. Larouche, D. Schmeisser and J.-P. Dodelet, J. Am. Chem. Soc., 2014, 136, 978; (e) C. H. Choi, H.-K. Lim, M. W. Chung, J. C. Park, H. Shin, H. Kim and S. I. Woo, J. Am. Chem. Soc., 2014, 136, 9070.

4 (a) A.-H. Lu and F. Schüth, Adv. Mater., 2006, 18, 1793; (b) H. Yang and D. Zhao, J. Mater. Chem., 2005, 15, 1217; (c) Q. Wang, Z.-Y. Zhou, Y.-J. Lai, Y. You, J.-G. Liu, X.-L. Wu, E. Terefe, C. Chen, L. Song, M. Rauf, N. Tian and S.-G. Sun, J. Am. Chem. Soc., 2014, 136, 10882. 5 (a) S. Holdcroft, Chem. Mater., 2014, 26, 381; (b) D. Yu, E. Nagelli, F. Du and L. Dai, J. Phys. Chem. Lett., 2010, 1, 2165; (c) G. J. Sohn, H. J. Choi, I. Y. Jeon, D. W. Chang, L. Dai and J. B. Baek, ACS Nano, 2012, 6, 6345; (d) I. Y. Jeon, H. J. Choi, S. M. Jung, J. M. Seo, M. J. Kim, L. Dai and J. B. Baek, J. Am. Chem. Soc., 2013, 135, 1386.

6 (a) G.-P. Hao, G. Mondin, Z. Zheng, T. Biemelt, S. Klosz, R. Schubel, A. Eychmüller and S. Kaskel, Angew. Chem., Int. Ed., 2015, 54, 1941; (b) K. Kaneko, Nat. Chem., 2015, 7, 194.

7 (a) D. D. Do, S. Junpirom and H. D. Do, Carbon, 2009, 47, 1466; (b) T. Matsuoka, H. Hatori, M. Kodama, J. Yamashita and N. Miyajima, Carbon, 2004, 42, 2329; (c) J. K. Brennan, K. T. Thomson and K. E. Gubbins, Langmuir, 2002, 18, 5438; (d) H.-J. Wang, A. Kleinhammes, T. P. McNicholas, J. Liu and Y. J. Wu, J. Phys. Chem. C, 2014, 118, 8474; (e) Y. Tao, M. Endo and K. Kaneko, J. Am. Chem. Soc., 2009, 131, 904; $(f)$ T. Ohba and K. Kaneko, J. Phys.: Conf. Ser., 2009, 177, 012001.

8 (a) W. Yang, X. Liu, X. Yue, J. Jia and S. Guo, J. Am. Chem. Soc., 2015, 137, 1436; (b) S. Zhao, H. Yin, L. Du, L. He, K. Zhao, L. Chang, G. Yin, H. Zhao, S. Liu and Z. Tang, ACS Nano, 2014, 8, 12660; (c) K. Ai, Y. Liu, C. Ruan, H. Lu and G. Lu, Adv. Mater., 2013, 25, 998.

9 (a) Z. Li, G. Li, L. Jiang, J. Li, G. Sun, C. Xia and F. Li, Angew. Chem., Int. Ed., 2015, 54, 1494; (b) R. Liu, D. Wu, X. Feng and K. Müllen, Angew. Chem., Int. Ed., 2010, 49, 2565.

10 (a) H.-W. Liang, X. Zhuang, S. Brüller, X. Feng and K. Müllen, Nat. Commun., 2014, 5, 4973; (b) G.-L. Tian, M.-Q. Zhao, D. Yu, X.-Y. Kong, J.-Q. Huang, Q. Zhang and F. Wei, Small, 2014, 10, 2251.

11 H. T. Chung, J. H. Won and P. Zelenay, Nat. Commun., 2013, 4, 1922.

12 (a) S. Zhao, H. Yin, L. Du, L. He, K. Zhao, L. Chang, G. Yin, H. Zhao, S. Liu and Z. Tang, ACS Nano, 2014, 8, 12660; (b) W. Yang, X. Liu, X. Yu, J. Jia and S. Guo, J. Am. Chem. Soc., 2015, 137, 1436; (c) N. R. Sahraie, J. P. Paraknowitsch, C. Göbel, A. Thomas and P. Strasser, J. Am. Chem. Soc., 2014, 136, 14486. 